\title{
THE PRAGMATICS OF HUMOR IN A SERIOUS STORY*
}

\section{LA PRAGMÁTICA DEL HUMOR EN UNA HISTORIA SERIA}

\author{
JEF VERSCHUEREN \\ University of Antwerp \\ jef.verschueren@uantwerpen.be
}

Recibido: 20/11/2016

Aceptado: 05/05/2017

\begin{abstract}
It is hard to imagine a text more serious than Saul Alinsky's Rules for Radicals: A Pragmatic Primer for Realistic Radicals (1971). It is what its title says, a set of guidelines for those aspiring to become organizers of societal change - revolutionaries of some kind, the 'realistic' kind. The guidelines are 'pragmatic' in its everyday sense, hence entirely downto-earth. Yet, humor comes in. This paper explores one of Alinsky's educational stories which clearly lacks overall humorous intent but still has the potential of scoring humorous effects. An analysis of the example is used to address the relationship between humor and seriousness. At the same time it illustrates how systematic attention to the calibration of explicit and implicit levels of meaning generation can be used in the investigation of humor. Some additional remarks are made about how the example relates to some of the common notions in theories of humor.

KEYWORDS: Humor, Seriousness, Narrative, Explicitness/Implicitness, Pragmatics.
\end{abstract}

\begin{abstract}
Resumen
Cuesta imaginar un texto más serio que Tratado para Radicales: Un Manual para Radicales Realistas de Saul Alinsky (1971). Es lo que el título dice, un conjunto de directrices para aquellos que aspiran a convertirse en los organizadores del cambio social - revolucionarios de alguna clase, de la clase realista. Las directrices son 'pragmáticas' en su sentido cotidiano y, por lo tanto, totalmente práctico. Aún así, el humor se introduce en él. Este trabajo explora una de las historias educativas de Alinsky que, sin tener un propósito humorístico, tiene, sin embargo, el potencial de conseguir efectos humorísticos. El análisis de este ejemplo servirá para hacer referencia a la relación entre humor y seriedad. Asimismo, ilustra cómo la atención sistemática a la calibración de la generación de los niveles del significado explícito e implícito se puede usar en la investigación del humor. Se harán algunas observaciones adicionales sobre cómo este ejemplo se relaciona con algunas de las nociones básicas en las teorías del humor.
\end{abstract}

PALABRAS CLAVE: humor, seriedad, narrativa, explicidad/ implicidad, pragmática.

\footnotetext{
* This paper was produced in the context of a collaborative project supported by the Spanish Ministry of Economy and Competitiveness through the grant FFI2015-64540-C2-1-P "Gender, humor and identity: Development, consolidation and applicability of linguistic mechanisms in Spanish" (MINECO-FEDER). It was first presented at the Workshop on Advanced Studies of Humor (WASHUM), 26-27 November 2015, in Alicante, Spain. I am grateful to ELUA's anonymous reviewers for pointing out where I was too careless.
}

Para citar este artículo / To cite this article: Verschueren, Jef (2017). The pragmatics of humor in a serious story. ELUA, 31: 311-326. doi: 10.14198/ELUA2017.31.16

Enlace / Link: http://dx.doi.org/10.14198/ELUA2017.31.16 


\section{INTRODUCTORY OBSERVATIONS}

When reading a recent pragmatics textbook such as Culpeper and Haugh (2014), it is striking how many of their examples to illustrate how ordinary language use works, are in fact jokes. Similarly, many of the examples to illustrate politeness and impoliteness in Kádár and Haugh (2013) are simply funny episodes from movies or television series. These observations made me wonder: If humor is so essential for pragmatics and specifically for politeness phenomena, did I ever write anything about humor? In my forty years of writing about pragmatic issues, the only episode I could find is the following:

Grice's theory of conversational implicature is predicated on a model of communication which attaches the highest normative value to demands for rationality and efficiency. As has often been observed in the pragmatic literature, however, social behavior also incorporates norms which would seem to require breaches of the maxims. [p. 35] Norms of politeness, in particular, often do not allow for fully informative utterances, unmitigated truth, or complete clarity (see also 1.2.). It is this intuition that was captured by Dan at a pretheoretical level when he made the metapragmatic statement Just trying to be polite in (1)8. Similarly, there are types of verbal activity, such as those covered by the label humour, which would barely be possible with complete adherence to the maxims (see Illustration 2) - though a stretch of discourse which follows the maxims diligently might itself turn out to be quite humorous for precisely that reason. Politeness and humor both exploit the impossibility of full explicitness strategically, using many of the mechanisms described by Grice, to generate implicated meaning. (Verschueren 1999: 35-36)

Not only is this, to the best of my recollection, the only written statement I ever made about humor - the same goes for politeness. ${ }^{1}$ Is it accidental, then, that I put these two phenomena, politeness and humor, in one paragraph in the only piece I have ever written about them?

Looking at what I say in the above quotation, and comparing it with Culpeper \& Haugh, for instance, there is a striking similarity. I talk about the exploitation of the impossibility of full explicitness. Culpeper \& Haugh give the first four examples in their book - all jokes in a section entitled "Beyond the linguistic code", which is about the relationship between coded, and therefore decodable meaning on the one hand, and the extra, implicit meaning that is communicated and understood on the other, and they say "[...] we will simultaneously explore a number of jokes, not least because jokes often exploit the construction of meaning" (Culpeper and Haugh 2014: 2). The examples are the following:

(1) A: Why can't a man's head be twelve inches wide?

B: Er ... don't know.

A: Because if it was, it would be a foot.

(2) Q: How do you make a cat drink?

A: Easy, put it in the liquidiser.

1 In Verschueren (1999) there are or course a few more examples that may seem 'funny' (notably an airline pilot's probably unintentional humor when apologizing for delays and saying over the intercom "Once we are in the air, we'll fly as fast as possible", followed by giggles among the passengers), but they were not thematized as part of a discussion of humor. 
(3) A man and a friend are playing golf one day. One of the guys is about to chip onto the green when he sees a long funeral procession on the road next to the course. He stops in mid-swing, takes off his golf cap, closes his eyes, and bows down in prayer. His friend says: "Wow! That is the most thoughtful and touching thing I have ever seen. You are truly a kind man."

The other man replies, "Yeah, well, we were married thirty-five years."

(4) I was coming back from Canada, driving through Customs, and the guy asked, "Do you have any firearms with you?" I said: "What do you need?"

Culpeper and Haugh go on to distinguish different aspects of the 'construction' of meaning they have in mind. Example (1) is a pun that depends on an assignment of sense to a polysemous word. Example (2) hinges on an assignment of structural meaning: the question can be parsed differently: drink as main verb of the embedded clause a cat drink vs. drink as head noun of a noun phrase pre-modified by cat. Example (3) requires an assignment of reference: the interpretation depends on working out the reference of we which, in combination with married, refers to a man and his wife, the woman for whom the funeral procession is held. Example (4) allows for different assignments of utterance meaning, in particular, different assignments of a specific speech act status to Do you have any firearms with you?

Culpeper and Haugh's summary: "Jokes, as we saw, often exploit the fact that meanings cannot be straightforwardly decoded from words and structures." (Culpeper and Haugh 2014: 5).

So we now have three notions to cope with: humor, politeness/impoliteness, and explicitness/implicitness. And two points present themselves for clarification:

(i) These three are not 'equivalent': both humor and politeness seem to need reference to explicitness/implicitness for their explanation.

(ii) The latter two seem to imply a somewhat bipolar scale. But what about humor then? Does it have 'seriousness' as it's opposite?

We will briefly go into (ii) first (in section 2), and then we will return to (i) (in section 3 ), i.e. the role of implicitness/explicitness as a conceptual tool to make sense of (ii).

\section{HUMOR AND SERIOUSNESS}

At first sight, seriousness would seem to be the opposite of humor, just like impoliteness is the opposite of politeness and implicitness is the opposite of explicitness - at least in everyday senses of the terms. One might object that unlike seriousness, denoting a quality or attitude, the term 'humor' refers to a form of behavior: a comical or amusing text or performance can be categorized as humor. But let's not forget that while this use of the word may be the default in what linguists write about humor, it is only a specialized sense deriving from a complex conceptual history (a) starting in medieval physiology where humor referred to any of the four body fluids (blood, phlegm, choler, melancholy) and their related qualities (hotness, coldness, dryness, moistness), (b) moving on to any mental quality, temperament or mood based on the relative proportions of the bodily humors, and 
(c) ending up with a person's ability to exhibit or appreciate amusing or comical occurrences or behavior. Certainly if we extend humor to one of its manifestations, joking, the objection fades away: "I'm serious" can be used on exactly the same occasion as "I'm not joking", which implies a rather clear and straightforward contrast or opposition.

Humor vs. seriousness would also seem to be an equally gradable phenomenon as the politeness/impoliteness and the explicitness/implicitness scales. But while the latter are commonly treated as scales, with phenomena such as mock impoliteness and teasing (which tests the hearer's capacity to appreciate face-threatening fun at his/her own expense), or forms of coded (and hence not entirely implicit) implicitness (such as presuppositions carried by specific forms of expression), i.e. phenomena to be found in border areas between the extremes, discussions of the humor/seriousness dichotomy show a different pattern. They either involve evaluation, as when the question is asked as to what turns parody (defined in terms of relatively innocent intent) into insult (defined in terms of uptake/interpretation) ${ }^{2}$, or they involve a denial of the dichotomy, stressing that humor and seriousness go together. Testimony of how humor and seriousness go together can be found in the statements of well-known people:

If you can get humor and seriousness at the same time, you've created a special little thing, and that's what I'm looking for, because if you get pompous, you lose everything. (Paul Simon)

Humor and seriousness are not in opposition to each other. (Al Franken)

Sheer playfulness and deadly seriousness are my closest friends. (Philip Roth)

Or consider NBA-player Shaquille O'Neal's doctorate on The duality of humor and seriousness in leadership styles (and the public appearances in which this duality is thematized; cf. https://www.youtube.com/watch?v=3kf6MQgxFvc).

Still, while it is possible to talk about aggressive humor or sarcastic humor, you don't hear about serious humor, in spite of the apparent possibility of interconnectedness of the two concepts. To explain this, we must keep in mind an ambiguity in the meaning of 'seriousness'. The seriousness referred to in "I'm serious" (used as another way of saying "I'm not joking") bears on the extent to which what is said (propositionally) must be taken literally, as a reflection of what the speaker holds as true. On the other hand, the seriousness referred to in the statements above pertains to overall communicative intent, a message the language user is trying to get across, as opposed to the possible jocularity of the style with which this is done. ${ }^{3}$ The possible interconnectedness or non-contrast, in this second sense, is also hinted at in the pragmatic literature, where humor is often studied in its capacity of serving specific serious purposes. Consider Pamela Hobbs' (2007) 'Judges' use of humor as a social corrective," Kazuyo Murata's (2014) "An empirical cross-cultural study of humour in business meetings in New Zealand and Japan," or Yu Wang's (2014) "Humor in British academic lectures and Chinese students' perceptions of it," to name just three examples. Court cases, business meetings, and academic lectures are serious

2 As recent events (as with the Danish Mohammed cartoons) have shown, both sides of the interpretive divide usually blame each other: for not appreciating the humor, or for not understanding the seriousness.

3 For a more sophisticated look at how 'jocularity' works, see Sinkeviciute (2016). 
stuff, yet humor occupies a place in them and may demonstrably serve the overall serious purposes. Conversely, failed humor may become a serious matter, as argued by Bell:

Although scholars recognize the many serious functions of humor, among lay people humor is generally considered as merely frivolous and fun, and this portrayal is easy to maintain when all goes well. However, as with a great deal of linguistic behavior, it is when expectations are not met that social norms are revealed. The responses presented here [i.e. responses to failed attempts at humor] suggest that, under some conditions, humor is not at all frivolous - if this were the case, its failure would be of little consequence and certainly not worthy of some of the more vehement responses that were collected. (Bell 2009: 161)

Among the many theories of humor, some focus specifically on why people use humor. More often than not, the explanations hinge on a subtle link with serious issues such as conflicts, solidarity, and power. Hay (2000) observes a gender difference, men often using humor to resolve conflicts, women to show solidarity. Holmes (1998, 2000) studies the workings of humor in the workplace, serving either as a subtle challenge to power or to de-emphasize one's own power. And of course there is the well-known relief theory of humor, presenting laughter as a basic mechanism to reduce tension. A recent manifestation of this function emerged when, after terrorist attacks in Paris, Brussels (where plans for the attacks were thought to have been made) went into lockdown. Authorities asked the population not to spread around pictures of what was happening in the streets, just to make sure that police searches could not simply be followed through the social media. Obliging this request, a twitter account (\#brusselslockdown) was started, spreading around numerous funny cat pictures:
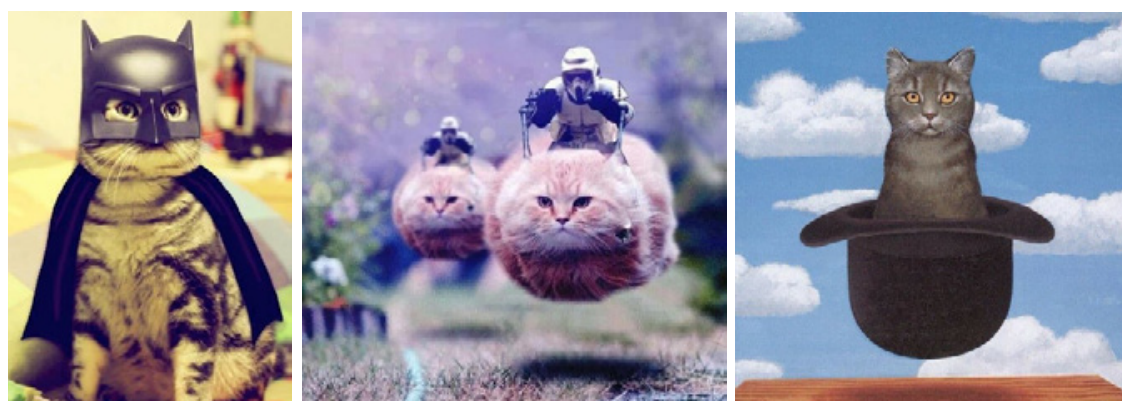

Figure 1. \#brusselslockdown.

After a few days, the police joined in, thanking the cats for their cooperation:

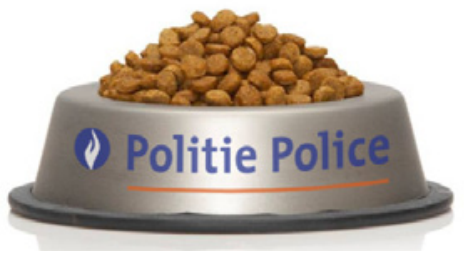

Figure 2. \#brusselslockdown (response). 
Maybe we must conclude that humor is simply central to (verbal) social interaction in general. But what about the observed seriousness of humor or the appeal to humor for serious causes, which seems to be so pervasive? Surely, this is a type of question that does not have a parallel in the politeness/impoliteness sphere. How does this symbiotic relationship between apparent opposites work? Theories of how humor works (as opposed to theories of why it is used), such as the incongruity-resolution theory, will no doubt come in. But what I am interested in is the nuts and bolts of the meaning-generating mechanisms involved. In section $3 \mathrm{I}$ will take a few steps in what I hope to be the right direction. But in order for this attempt to be successful, I need a good example.

It is hard to imagine a text more serious than Saul Alinsky's (1971) Rules for Radicals: A Pragmatic Primer for Realistic Radicals. The book is what its title says, a set of guidelines for those aspiring to become organizers of societal change - revolutionaries of some kind, the 'realistic' kind. The guidelines are 'pragmatic' in its everyday sense, hence entirely down-to-earth. Yet, humor comes in. First of all, humor is a tool for conveying serious messages; hence, some of the guidelines are themselves phrased in funny ways. Consider "A tactic that drags on too long becomes a drag" (p. 128). Second, some of the educational stories that are told clearly lack humorous intent, and still they have the potential of scoring humorous effects. One such story is told when trying to illustrate the need to find common experiences as a basis for successful communication. Alinsky reports on a little experiment he did to convince his trainees during a workshop for aspiring 'radicals.' The reported event was his walking around the Biltmore Hotel in Los Angeles, followed by a few of his trainees, and trying to give passers-by a ten-dollar bill. The reactions of those passers-by form the content of the story (which is quoted in full below).

\section{THE PRAGMATICS OF HUMOR IN A SERIOUS STORY - BACK TO EXPLI- CITNESS/IMPLICITNESS}

My goal is to analyze aspects of the meaning-generating that goes on in Alinsky's story, with a focus on one of the basic pragmatic mechanisms, the calibration of explicit and implicit meaning. To that end, I will make use of a descriptive three-dimensional matrix that can be handled for talking about implicitness. ${ }^{4}$ Though there is no space here to argue at length for the specific properties of this matrix, I must quickly identify the underlying assumptions. The first assumption is that implicitness-explicitness is not a dichotomous but a gradable distinction. Not all implicit meaning is equally implicit. Thus there is a dimension of 'salience', determined by the accessibility and processing costs related to specific carriers of implicit meaning. The second is that the gradability is not one-dimensional in the sense that specific linguistic phenomena could be nicely located along a single implicit-explicit axis. For one thing, there is also the local strategic interplay between a carrier of implicit meaning and its linguistic environment and non-linguistic context. This means that both the dimensions of 'structure' and 'context' are involved as well, yielding the three-dimensional matrix in Figure 3.

4 I have used the same descriptive technique for other purposes in Verschueren (2016) - which is why the following couple of paragraphs are near-identical to the ones I needed to explain the model in that earlier publication. 


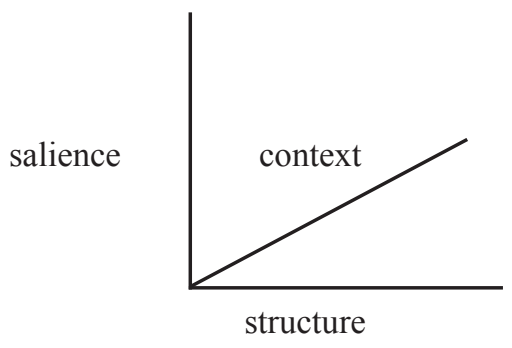

Figure 3. Three dimensions of implicitness.

In principle, these three dimensions (corresponding to three of the four angles from which to approach linguistic adaptability phenomena) $)^{5}$ should enable us to plot meaning landscapes (reflecting the dynamics involved, i.e., the fourth, most central, angle). In actual practice it is much harder, and it is not an understatement to say that at this moment I can only do this intuitively. No doubt, 'salience' can be measured to a certain extent; for instance, significant advances have been made in experimental pragmatics that enable us to distinguish between types of generalized conversational implicatures in terms of processing time and effort (Doran et al. 2012); but this type of work is available only for a very restricted set of phenomena. Probably 'structure' is the easiest dimension, as the structural locus of a trigger of meaning can be described in terms of well-established linguistic categories. 'Context' is a bit more complicated again, since the relevant elements are occasion-specifically determined by the lines of vision or the points of orientation adopted by the interlocutors.

When representing analyses based on this analytical matrix, a 'flat' diagram can be used, in which the structural dimension simply follows the sequential linear ordering of structural elements, in which such sequentially ordered structural elements are linked with aspects of meaning that represent contextual indexing, and in which these two levels (structure and context) are separated by different layers standing for degrees of salience (to be identified, as said before, in an intuitive manner, but using as a rule of thumb that the more likely an element of meaning is to be questioned, the closer it will be to the surface of explicitness). See Table 1. Note the terminological jump I make from 'context' to 'contextual indexing.' In fact, context itself must be described in terms of aspects of inferable meaning rather than in terms of 'naked' aspects of context: what implicitness/explicitness is all about is the variable ways in which forms index context (and in which we infer meaning from forms in context).

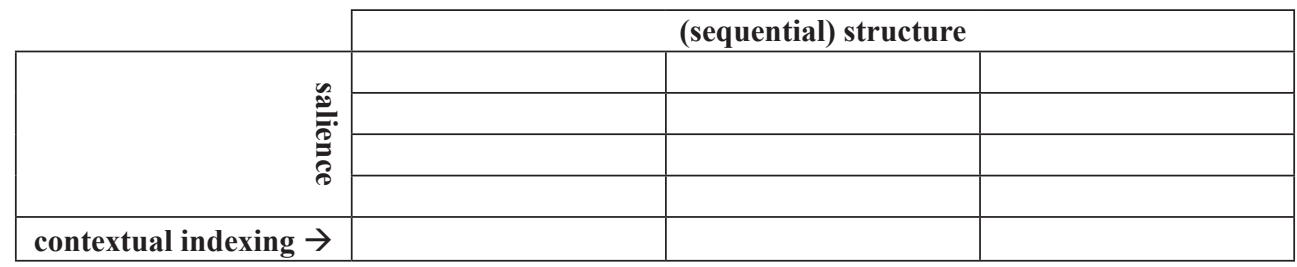

Table 1. Representational diagram.

5 Reference is made here to the theoretical framework for a pragmatic theory sketched in Verschueren (1999). 
But let's get down to work. Following is the story to be analyzed:

I walked around, trying to give the ten-dollar bill away. The reactions were all "within the experiences of the people." About three of them, seeing the ten-dollar bill, spoke first - "I'm sorry, I don't have any change." Others hurried past saying, "I'm sorry, I don't have any money on me right now," as though I had been trying to get money from them instead of trying to give them money. One young woman flared up, almost screaming, "I'm not that kind of a girl and if you don't get away from here, I'll call a cop!" Another woman in her thirties snarled, "I don't come that cheap!" There was one man who stopped and said, "What kind of a con game is this?" and then walked away. Most of the people responded with shock, confusion, and silence, and then quickened their pace and sort of walked around me.

After approximately fourteen people, I found myself back at the front entrance of the Biltmore Hotel, still holding my ten-dollar bill. My four companions had, then, a clearer understanding of the concept that people react strictly on the basis of their own experience. (From: Saul D. Alinsky, Rules for Radicals, p. 87)

Keeping in mind the entire context (sketched at the end of section 2), this text requires at least four levels of pragmatic analysis, indicated with roman I to IV in Table 2.

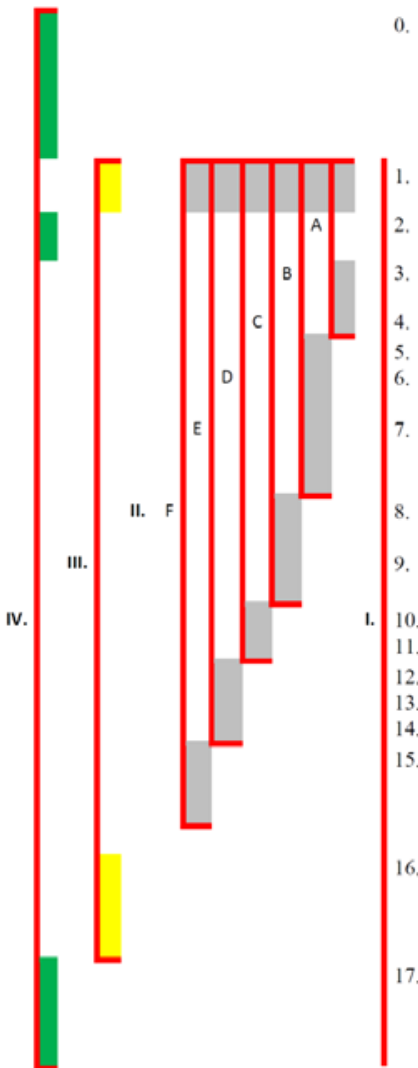

0. [When trying to illustrate the need to find common experiences as a basis for successful communication, $A$. does a little experiment walking around the Biltmore Hotel in Los Angeles, trying to give passers-by a ten-dollar bill.]

I walked around, trying to give the tendollar bill away.

The reactions were all "within the experiences of the people."

About three of them, seeing the ten-dollar bill, spoke first

- "I'm sorry, I don't have any change."

Others hurried past saying,

"I'm sorry, I don't have any money on me right now,"

as though I had been trying to get money from them instead of trying to give them money.

One young woman flared up, almost screaming,

"I'm not that kind of a girl and if you don't get away from here, I'll call a cop!"

Another woman in her thirties snarled,

"I don't come that cheap!"

There was one man who stopped and said, "What kind of a con game is this?" and then walked away.

Most of the people responded with shock, confusion, and silence, and then quickened their pace and sort of walked around me.

16. After approximately fourteen people, I found myself back at the front entrance of the Biltmore Hotel, still holding my tendollar bill.

17. My four companions had, then, a clearer understanding of the concept that people react strictly on the basis of their own experience.

Table 2. Levels of analysis. 
Level I (1 to 17) is the phrase and sentence level.

Level II (A to F) is an embedded interaction level, involving three types of 'actor':

- $\mathrm{A} 1=$ the person 'offering' the ten-dollar bill;

- $\mathrm{A} 2$ = the people reacting;

- $\mathrm{A} 3=$ the trainees following $\mathrm{A} 1$ and observing the interaction.

Level III is the narrative level, with

- $\quad$ an author A (who is identical to A1 at level II)

- and readers R.

Level IV is the (serious) story level,

- also involving $\mathrm{A}$ and $\mathrm{R}$,

- but also the actors in the background educational context:

$\mathrm{o}$ the trainer $\mathrm{T}$ (who is identical to A1 at level II and A at level III)

$\mathrm{o}$ and students $\mathrm{S}$ (who are identical to $\mathrm{A} 3$ at level II).

Let us look at the four levels of analysis one by one. At each level, there is a lot more to be analyzed, in terms of the calibration of explicit and implicit meaning, than what is immediately relevant in this context. Just look at sentence 1: $I$, a case of person deixis, is referentially indeterminate; walked around, a case of spatial deixis, is in itself equally indeterminate; trying implies an expectation of difficulty; to give away evokes a transactional frame or script involving an actor, an action, an object, and a beneficiary or target; the ten-dollar bill is a definite description carrying an existential presupposition, and dollar is underspecified with respect to the type of monetary system. All potential uncertainties (i.e. meanings left implicit) are, however, resolved (i.e. potentially brought to the surface of interpretational explicitness) for the reader given the available intratextual correspondences. Most of what there is to be analyzed at level I (the phrase and sentence level) is of this kind. Choices that are made at that level, however, make clear contributions to the effects scored at higher levels of structure.

Things that are immediately relevant for an understanding of the amusing nature of the story start happening at level II, which is the level of six embedded interactions (labelled A to F), which all have as their first pair part the 'offer' described in sentence 1, which is clearly conceived as an attempt to break expectations. In each case, the second pair part is linked to the first pair part by means of a form of (sometimes overtly interpretive) metapragmatic framing: spoke first in 3, saying in 5, flared up and almost screaming in 8, snarled in 10, said in 12, responded with shock, confusion, and silence in 15 . The sequential format is constant, except that in B an interpretive phrase is appended at the end, and F provides a summary of the previous five episodes. But the content varies, showing different ways of restoring interpretability of the unexpected. It is these differences in content that I will try to describe, using the representational tool proposed in Table 1.

Various types of meaning-generating mechanisms are represented in Table 3 (as in the following tables, 4 through 7, as well). The main challenge is to try and understand the way in which surface structure and meaning are linked to contextually anchored ('indexed') interpretations. In order to represent what happens in terms of contextual indexing, two questions need to be asked. 


\begin{tabular}{|c|c|c|}
\hline $\begin{array}{c}\text { I walked around trying to give } \\
\text { the ten-dollar bill away }\end{array}$ & $\begin{array}{c}3 \\
\text { About three of them, seeing the } \\
\text { ten-dollar bill, spoke first }\end{array}$ & $\begin{array}{c}4 \\
\text { "I'm sorry, I don't have any } \\
\text { change." }\end{array}$ \\
\hline & & \\
\hline
\end{tabular}

Table 3. Embedded interaction A.

First of all, how salient is a given connection between a form of expression and its related contextual meaning? In other words, how much processing effort does it require to interpret? Or, since the experimental tools to measure salience in those terms are not readily available, what is the answer to the following rule-of-thumb question: how likely is it for a specific aspect of contextual, inferred meaning, to be questioned or challenged? Though responses to such a question remain intuitive, for now, the more likely the challenge, the closer the meaning will be to the surface (i.e., the more salient explicit it will be), the less likely the challenge, the 'deeper' (i.e. less salient, more implicit) it will be. It is the intuitive estimates in relation to these questions that determine placement of a dot ( $\mathbf{})$ in a specific layer (at a specific 'depth') between surface forms and contextual meanings in the Table. In relation to sentence 1, for instance, the 'offering' of money is described quite literally, which is why the corresponding dot is in the upper layer (which still does not mean that all aspects of its meaning are totally explicit in that sentence the breach of expectations which is involved depends interpretatively on the immediately preceding text), while the educational background frame does not only require reference to the preceding text but remains completely inaccessible to some of the participants (A2) in the interaction that is described (which is why the dot is far down, though with a link - to be explained later - with the surface 'offering'). Similarly, in sentence 3 the focus on immediacy of reaction, inferable from the metapragmatic framing of the following utterance (sentence 4), is not entirely explicit; yet it does not require much processing effort to arrive at; hence placement in the second layer. In sentence 4, the money-changing script on which non-compliance with the offer is based, is close to the surface (even the word change comes in literally) but not entirely immune to challenge; hence placement relatively high up, but not all the way. 
A second question pertains to the relationships between the different elements of contextual indexing (represented by the dots). There are at least five relevant types of relationship:

(i) Simple sequentiality (represented in Table 3 by means of a simple full line); thus the 'offer' in 1 is followed by non-compliance in 3 .

(ii) An overt textual link (a full line with an arrow head); thus the metapragmatic framing in 3 bears on the utterance in 4 .

(iii) An implicit conceptual link (dotted line with an arrow head); thus the educational background frame in 1 is needed to fully understand the 'offering' of money, and the implicit money-changing script in 4 provides the basis for non-compliance with the 'offer.'

(iv) A contrast (double-arrowed dashed line); thus the money-offering script in 1 is incompatible with the money-changing script in 4.

(v) Disconnection (not visually represented); thus the educational background frame, which is only accessible to A1, A3, A, R, T, and S, and which excludes A2, is entirely disconnected from the utterance in 4 .

The overall picture is very similar for the other embedded interactions, as presented in Tables 4 through 7 .

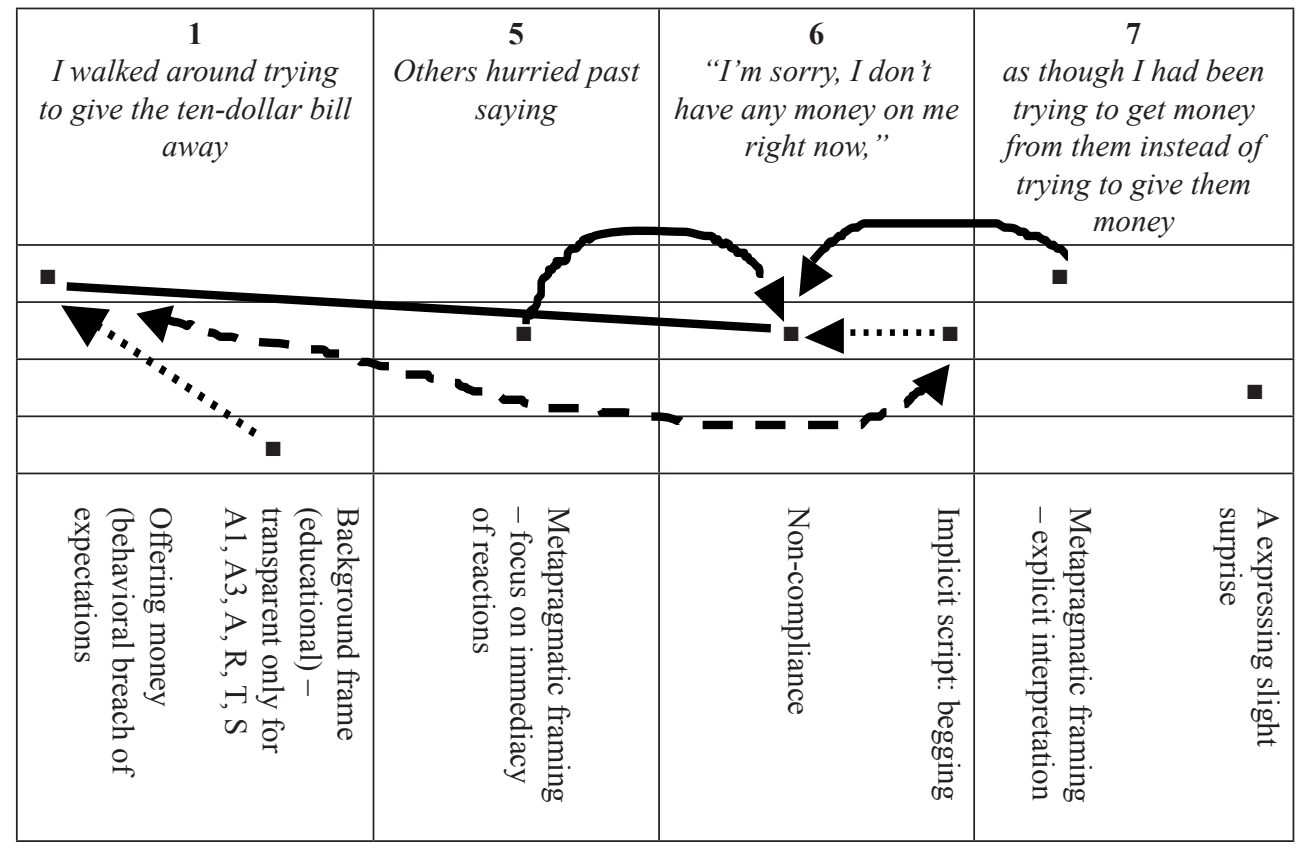

Table 4. Embedded interaction B.

The only differences with A are that in 6 a different incompatible script is relied on as a basis for non-compliance with the offer in 1, and that further metapragmatic framing is added at the end (in 7) which explicitly reveals the incompatibility of the scripts; this further framing also suggests the author's surprise at the script evoked in 6. 


\begin{tabular}{|c|c|c|}
\hline $\begin{array}{c}1 \\
\text { I walked around trying to give } \\
\text { the ten-dollar bill away }\end{array}$ & $\begin{array}{c}\mathbf{8} \\
\text { One young woman flared up, } \\
\text { almost screaming }\end{array}$ & $\begin{array}{c}\text { "I'm not that kind of a girl, and } \\
\text { ifyou don't get away from here, } \\
\text { I'll call a cop!"” }\end{array}$ \\
\hline & & \\
\hline
\end{tabular}

Table 5. Embedded interaction C.

Here the re-scripting in 9 underlies two actions rather than one: in addition to noncompliance there is also a threat. The focus of the metapragmatic framing shifts accordingly.

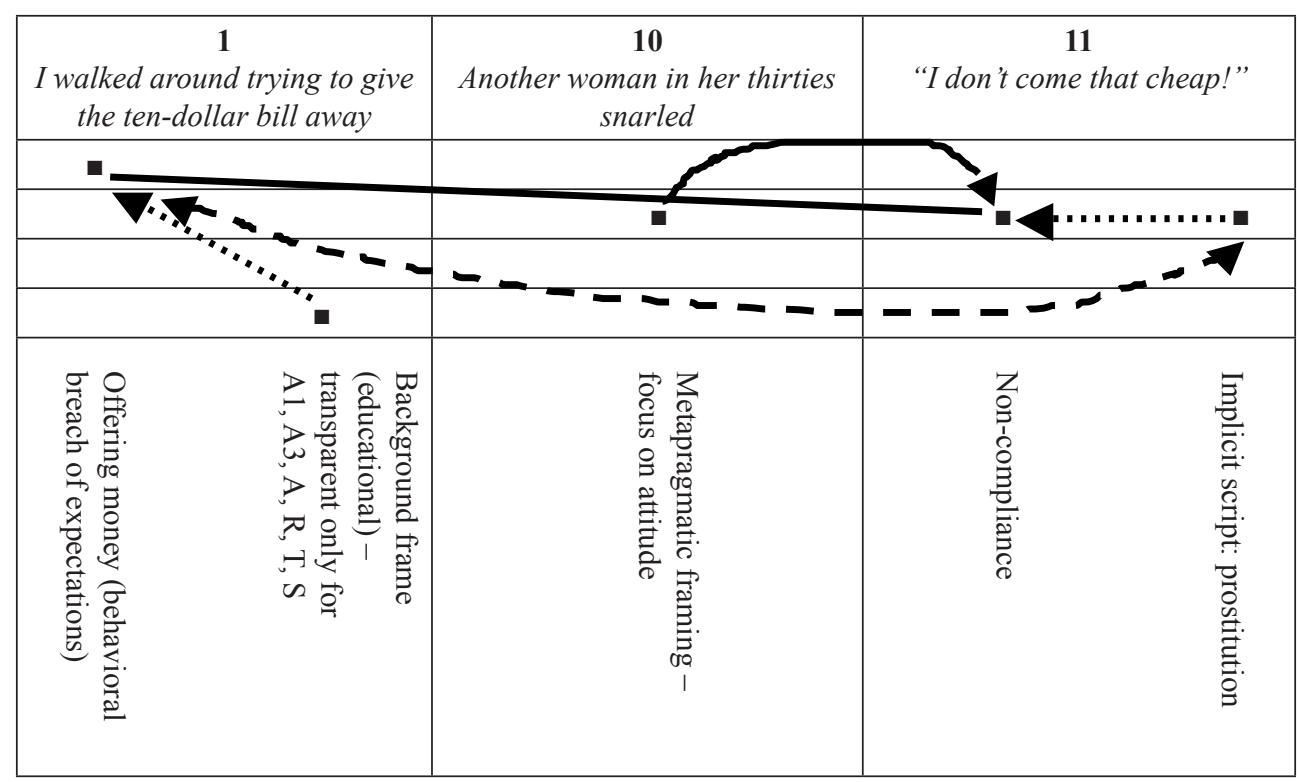

Table 6. Embedded interaction D. 
Structurally, this exactly like Table 3, but the content of both the implicit script in 11 and the metapragmatic framing in 10 differs. A slightly new picture we get in Table 7, not only with a new interpretive script and a different focus in the metapragmatic framing, but also with a different form of sequentiality (linking 14 to 12 ).

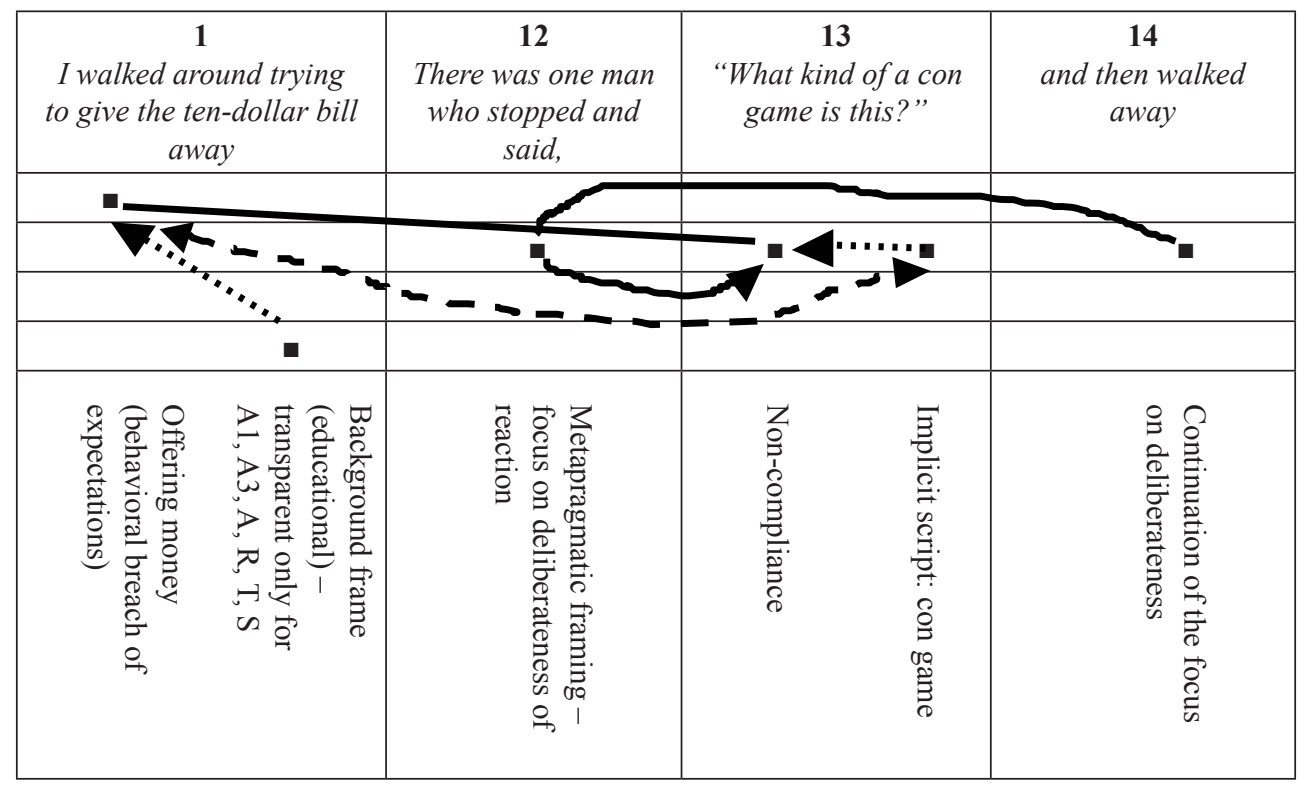

Table 7. Embedded interaction E.

The embedded interactions are concisely summarized in $\mathrm{F}$ in terms of an action-reaction framework, with 1 describing the action and 15 the expected reaction to the expectationbreaching behavior of the author. In all those cases, the humorous or amusing effect seems to derive from the incongruity between the educational background frame on which the matterof-fact surface interpretation of the action described in 1 is based, and the reinterpretation underlying the reactions, prompted by the lack of access to the educational frame, the rare occurrence of people trying to give away money in the street, and hence the need to make sense of what is happening in terms of scripts that seem possible, if not plausible.

At level III, then, we find the narrative frame, with an opening in 1 (describing the attempt to give away a ten-dollar bill) and a clear closing in 16 (describing the failure to do so). In terms of what is interesting for this paper, what is happening is all very straightforward, even if sentence 16 requires, for its interpretation, access to the embedded interactional episodes A to E and (less crucially) their summary in F.

In contrast to the attempt-failure scenario in the narrative frame, the serious story level, level IV, has a goal-success structure. The introductory 0 (put between square brackets since it is not part of the text but rather my summary of the preceding text) provides an explicit sketch of the educational goal and the experiment set up to achieve it. After an intervening anticipatory summary of reactions to the opening move in 2 , the end result, educational 
success, is described in 17. While both 0 and 17 are (in terms of aspects of meaning relevant for this paper) quite explicit, 2 would be much further down on the scale of salience/ explicitness in a diagrammatic representation similar to the ones in the foregoing tables.

\section{UNDERSTANDING HUMOR IN A SERIOUS STORY}

There is bound to be an uneasy relationship between the foregoing description of aspects of meaning generation in a funny serious story, and some standard theories of humor, if for no other reason because the type of example deviates from what is commonly analyzed. The question we are still stuck with is, therefore: Why (and how) is this funny?

Among the standard concepts for explaining humor, there is the notion of incongruity. Simplifying a vast literature about this, the account goes as follows: a piece of discourse is produced which incorporates, to use Raskin's (1985) terminology, (aspects of) two 'scripts' (frames of interpretation) which are (at least partly) in opposition with each other, i.e. which are incongruous. A humorous effect is then scored when the incongruity gets resolved. Typically this happens, for instance in a joke, at the end when it becomes clear that an initial interpretation in terms of one script must be replaced by interpretation in terms of the other script.

Clearly, there is incongruity involved in our serious story. But this is the case at different levels. At level II, in each of the embedded interactions (A through E) there is an opposition between the explicit 'offering money' script which they all start out with and the more implicit script in terms of which actor A2 responds (from changing money and begging to prostitution and a con game). This is the incongruity represented by means of the doublearrowed dashed lines in Tables 3 to 7 . There is an even stronger incongruity at the interface between levels II and IV: A2's interpretation scripts at level II are completely detached from the educational script at level IV which underlies the 'offering money' script; hence there is no connecting line at all in Tables 3 to 7 . But in neither case is there any incongruity resolution in the sense that there would be a joke-like abrupt transition from interpretation in terms of one script to interpretation in terms of another. What makes the interactional events at level II funny is the fact that A1 and A3 expect a form of re-scripting on the part of A2, without being able to predict what shape it will take. Similarly, R at levels III and IV is led to expect A2's re-scripting and will normally react with a healthy degree of surprise at the specific shapes the different responses take. ${ }^{6}$ The term 'incongruity resolution', then, can only be used here if it is also made applicable to an 'understanding' of the unpredictable specific shape of an expected type of incongruity. Such 'resolution' is there for all actors involved (A1, A3, A, R, T, S) except A2. What is happening is not meant to be funny for $\mathrm{A} 2$, because the incongruity is not meant to be recognized by him or her.

Another common notion to explain humor is to categorize it, like lying, as a type of nonbona-fide modes of communication. Again simplifying the literature a bit, the distinguishing criterion to recognize bona-fide vs. non-bona-fide communication is that the former adheres to the Gricean maxims of conversation whereas the latter does not. In particular, humor would often involve attempts to mislead, to 'prime' in the wrong direction, up to a point.

6 Here a link can be made with Giora's (1991) emphasis on the element of surprise to explain jokes. We must remember, though, that the story we are analyzing can in no way be categorized as a joke. 
Clearly, our funny serious story does not fit that characterization at all. At level II, there is no attempt at all to mislead, even if background motivations for offering money remain hidden: A2 is free to accept the money. Not having access to A1's context of the educational experiment, A3 remains at his/her primary context level where giving away a ten-dollar billing to people one does not know is unexpected deviant behavior which, therefore, must be given extra non-surface meaning. ${ }^{7}$ At the higher levels of analysis, III and IV, which is where the humorous effects are scored, this is a straightforward narrative which honors Grice as well as any narrative can.

Summarizing, the closest we may come to explaining why the story is funny is to point at the unpredictability of the specific manifestations of an expected form of incongruity.

\section{CONCLUDING THOUGHTS}

Having tried to explain why Alinsky's story is funny, and having shown some of the meaning-making mechanisms that are involved, we may still have to explain why the story is less funny than a corresponding candid-camera episode. After all, while being amused, one does not get a laughing fit when reading it. Probably this is due to the degree of explicitness with which the educational framing is provided. Another remaining question is, then, whether the same educational effect could be reached without at least telling or asking, if not doing, something that would break expectations. Probably not, so that a certain type or degree of humor would seem essential to an achievement of the serious goal.

\section{References}

Alinsky, Saul D. (1971). Rules for Radicals: A Pragmatic Primer for Realistic Radicals. New York: Vintage Books.

Attardo, Salvatore (2003). "Humor," in J.-O. Östman and J. Verschueren (eds.), Handbook of Pragmatics. Amsterdam: John Benjamins.

Bell, Nancy D. (2009). "Impolite responses to failed humor", in N.R. Norrick and D. Chiaro (eds.), pp. 143-163.

Culpeper, Jonathan and Michael Haugh (2014). Pragmatics and the English Language. Basingstoke: Palgrave Macmillan.

Doran, Ryan, Gregory Ward, Meredith Larson, Yaron McNabb and Rachel Baker (2012). "A novel experimental paradigm for distinguishing between what is said and what is implicated", Language 88(1), pp. 124-154.

Giora, Rachel (1991). "On the cognitive aspects of the joke", Journal of Pragmatics 16(5), pp. 465-485.

Hay, Jennifer (2000). "Functions of humor in the conversations of men and women", Journal of Pragmatics 32(6), pp. 709-742.

Holmes, Janet (1998). "No joking matter! The functions of humor in the workplace", Proceedings of the Australian Linguistics Society Conference (http://www.als.asn.au/proceedings/als1998/holme358.html).

- (2000). "Politeness, power and provocation: How humor functions in the workplace", Discourse Studies 2(2), pp. 1-17.

7 This step from observing unexpected behavior to the assumption that 'something else' must be going on, is purely Gricean logic. That means that Gricean logic is also applicable on certain types of occasions where no Gricean principles are violated. 
Hobbs, Pamela (2007). "Judges'use of humor as a social corrective”, Journal of Pragmatics 39(1), pp. 50-68.

Kádár, Dániel and Michael Haugh (2013). Understanding Politeness. Cambridge: Cambridge University Press.

Murata, Kazuyo (2014). "An empirical cross-cultural study of humour in business meetings in New Zealand and Japan", Journal of Pragmatics 60, pp. 251-265.

Norrick, Neal R. and Delia Chiaro (eds.) (2009). Humor in Interaction. Amsterdam: John Benjamins.

Raskin, Victor (1985). Semantic Mechanisms of Humor. Dordrecht: Reidel.

Sinkeviciute, Valeria (2016). "It's never meant to be offensive...": An Analysis of Jocularity and (Im) politeness in Australian and British Cultural Contexts. University of Antwerp PhD thesis.

Verschueren, Jef (1999). Understanding Pragmatics. London: Edward Arnold / New York: Oxford University Press. (Now downloadable in open access from http://anet.uantwerpen.be/docman/ irua/03eb70/20735.pdf.)

- (2016). "Humanities and the public sphere", Pragmatics and Society 7(1), pp. 141-161.

Wang, Yu (2014). "Humor in British academic lectures and Chinese students' perceptions of it", Journal of Pragmatics 68, pp. 80-93 